\title{
Advanced Practicum Experience: A Bitter Sweet Symphony
}

Kristen James Nunezn, RN, MN (Advanced Practice)

Nurse Practitioner and NIDCAP professional, Grace Centre for Newborn Intensive Care, The Sydney Children's Hospitals Network, Westmead, Australia

\section{Background}

A component of NIDCAP training and the final project prior to NIDCAP certification, is the NIDCAP Advanced Practicum (AP). This involves following the journey of a newborn infant and their family through their NICU stay, completing systematic observations and formal write-ups of their progression. The provision of feedback to nursing, medical and allied health teams as well as the newborn's family aims to support their growth and development in the NICU.

This is a reflective paper of my experience following the death of the baby I had chosen for my advanced practicum. Having worked closely with the family for almost four weeks when the baby died following complications from his congenital disease, I was left feeling quite devastated. In this paper I discuss the impact of this event on my NIDCAP training, and my subsequent progression to a certified NIDCAP professional. I describe the challenges I faced following this death and have titled this paper, A Bitter Sweet Symphony as I reflect on this experience with sadness, gratitude and hope.

\section{Introducing William}

I would like to introduce you to William Schrader, the baby I chose for my advanced practicum. William is a beautiful little boy born at 38 weeks gestation on the 13th September 2012. $\mathrm{He}$ entered this world after his mother had an elective caesarean section following an antenatal diagnosis of a congenital anomaly. At birth William weighed 3400 grams or 7 pounds, 5 ounces. He was born at a high risk obstetric centre and transferred to the adjoining Grace Centre for Newborn Intensive Care at The Children's Hospital within 24 hours following birth for management of a left congenital diaphragmatic hernia.

William is the second child to parents Olivia and Grant and a little brother to sister Elenor.

I chose to work with William and his family for my advanced practicum to demonstrate the importance of having NIDCAP training in a surgical newborn intensive care unit as a way of supporting these complex and fragile infants.

\section{William's Story}

William was incredibly fragile in his pre-surgery period and required intubation and mechanical ventilation soon after birth. $\mathrm{He}$ also required high level intensive care including inotropes for circulatory support, nitric oxide for respiratory failure, heavy sedation and muscle relaxation to support mechanical ventilation. He was deemed stable on day four following birth which enabled him to be transferred to the operating theatre for surgical repair of his diaphragmatic hernia. William underwent surgery on the 17 th September requiring a patch closure of his left diaphragm.

His post-operative course was also turbulent requiring high frequency oscillatory ventilation (HFOV), nitric oxide, steroid

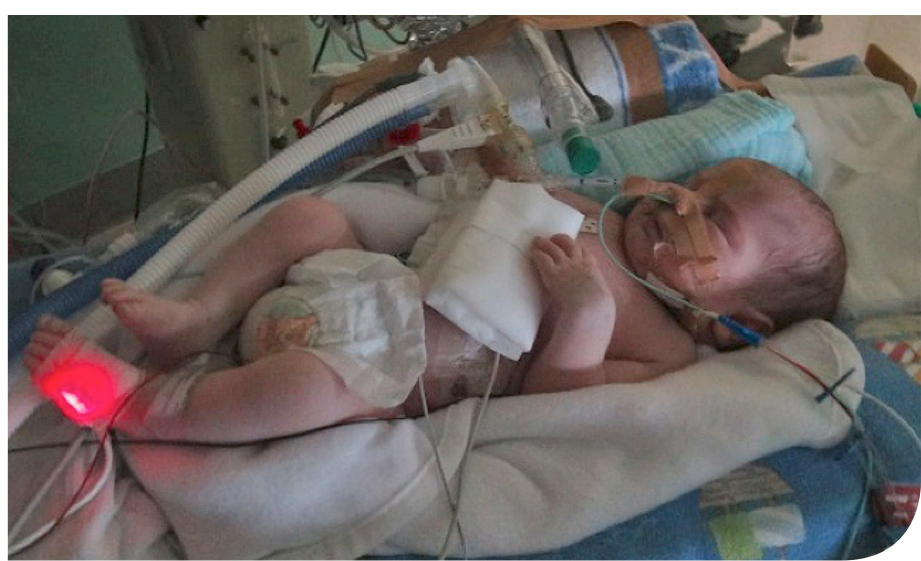

William at 4 days of age

therapy, multiple inotropic drugs, heavy sedation and muscle relaxation for prolonged periods over the course of the next 20 days.

He was able to be weaned from mechanical ventilation to continuous positive airway pressure (CPAP) for a brief period, however his condition deteriorated requiring escalation in medical management. He required sensitive and individualised nursing care to minimise the stress and to avoid physiological fluctuations that could compromise his stability.

William's condition deteriorated further and with maximum support being offered in the NICU, he was transferred to the adjoining Paediatric Intensive Care Unit for extracorporeal membrane oxygenation (ECMO). After six days on ECMO with no improvement in his condition, and following discussions with his parents and the health care team, a decision was made to discontinue ECMO as it was deemed a futile treatment at this stage. William died on the 7th October 2012 at 24 days young in the arms of his mother being cradled by his father.

An estimated 140 pregnancies are diagnosed with congenital diaphragmatic hernia $(\mathrm{CDH})$ in Australia and New Zealand each year, with less than half expected to survive. ${ }^{1}$ Being the largest referral centre in New South Wales, the Grace Centre for Newborn Intensive Care sees approximately 10 babies each year, with a survival rate of $97 \%$ across the NICU.

\section{Advanced Practicum - NIDCAP observations}

I first met William and his parents Olivia and Grant on the 14th September 2012 when he was transferred to our unit at two days of age. I spoke to Olivia and Grant about the role of developmentally supportive care for babies who have had surgery, the NIDCAP philosophy and the NIDCAP Advanced Practicum (AP). Olivia and Grant were keen for William to have this opportunity so I commenced my AP working closely with them throughout William's stay in the NICU. I completed my first NIDCAP observation and report that included my observations and subsequent recommendations for William's care on this day. My further observations and reports occurred throughout his 
time in the NICU. I took the opportunity to have members of my team record some videos which enabled me to adjust my recommendations for William. Babies who have had surgery and/or complex medical issues often have rapid changes in their condition requiring changes in the recommendations for support. These small videos often occurred in my absence due to my work schedule and provided a quick snapshot of William that supported adjustments to my recommendations.

I placed a folder at William's cot-side [bedside] with copies of the reports and recommendations. This enabled his parents as well as the nurses caring for William to read them each day. The goal was to enable the recommendations for William's care to be used by all staff to provide a consistent approach when his condition was quite unstable. When William was transferred to the adjoining Paediatric Intensive Care Unit for ongoing medical care and ECMO, I met frequently with Olivia and Grant to remain current with William's condition and fragility.

Due to William's condition and his need for such intensive medical support, heavy sedation and prolonged periods of muscle relaxation, his NIDCAP goals and recommendations were limited and unable to progress throughout his short life. However the benefit of observing William and discussing these observations with his parents were an instrumental focus of the AP.

\section{Challenges and rewards}

This experience came with many challenges but also great rewards. The challenges I faced included:

- Time: I had a lot of things going on at the same time as my NIDCAP training and completing the advanced practicum component. I was completing my Master of Advanced Practice at the University part time, in addition I was also preparing for the birth of my first child and the commitment required for my Advanced Practicum became stressful.

- Distance from NIDCAP trainer: This was slightly difficult with me in Australia and my trainer in the USA. Although I always felt supported throughout my NIDCAP journey, the distance between myself and Joy Browne, my NIDCAP trainer, did not allow for immediate feedback and consultation which left me feeling a little stranded. I felt in this situation I would have benefited from having my trainer closer. In addition the time difference of 15 hours made communication difficult.

- Unfamiliar situation: The distance was confounded further as I was not familiar with the recommendations in this situation and it was my understanding the death of a baby during a NIDCAP AP was a rare occurrence which left me unclear of what direction to take. I also found it difficult to articulate the relationship I had formed with the Schrader family through emails, missing that face-to-face discussion and simultaneous support.

- Shift work: Working shifts was also a challenge. At the time of this AP I worked three 12 hour shifts each week. The acute clinical work load on a specific shift sometimes meant completing NIDCAP observations and the write-up work required commitment outside of my working hours.
- William's Medical condition: William was extremely unwell from birth to his death which placed a great deal of difficulty on completing NIDCAP work and was a huge personal and emotional commitment for myself.

- My own personal health: I was 27 weeks pregnant when commencing this AP journey. This challenged me from a lethargy perspective as it added another component to my already busy life. My pregnancy also challenged Olivia and Grant as through their own stress and grief they showed great concern about the effect my commitment to William and their family may be having on my unborn child, something I had not anticipated.

Although difficult, the significant challenges made the rewards much more meaningful. The rewards I gained from this experience were immense:

- I am incredibly proud of the relationship I formed with the Shrader family. The AP work involved speaking with them about their son aside from the medical care, diagnosis and treatment, and focusing on their baby, their William. They commented often that these conversations allowed them to see through the tubes, machines and alarms forming memories they hold onto even today. Following William's death I provided them with a small video of all the movies and photos taken throughout our NIDCAP journey. I said my goodbyes to William when I attended his funeral, for which Olivia and Grant were so grateful.

- Professional learning and personal growth: This experience amplified to me the importance of supporting families through the medical haze of the NICU environment. It is so vitally important to support parents to have glimpses of their babies as just that, a baby, and not the ' 24 weeker' with chronic lung disease or the term baby with multiple congenital anomalies. I will forever take this into all my interactions with parents and this remains a focus of my care. I know I have William, Olivia and Grant to thank for that.

\section{Outcome}

Death and dying are an unfortunate part of the NICU journey for a small number of babies and families. This experience has shown me the relationships we make with these families is THE most important part of our NIDCAP work. The NIDCAP Federation International (NFI) now specifically addresses the importance of this relationship with the goal of supporting NIDCAP trainees during their AP.

"If the infant you are observing is or should become severely ill, and perhaps die, be aware of the importance of your supportive role, which becomes even more valuable in such circumstances. The family will greatly appreciate the developmentally focused input you provide and will treasure the diary of their infant. Avail yourself of the guidance of the professional in your setting skilled in the support of parents who experience the severe illness or death of their child. Depending on the length of the infant's life, you may wish to observe another infant, in order to gain sufficient experience in the context of your practicum. ${ }^{\prime 2}$ 


\section{Conclusion}

My journey to become a NIDCAP certified professional came with many challenges but also immense rewards and significant learning. I take the lessons I learned working so closely with William and his family into my clinical practice each day. My role within the NICU as a Neonatal Nurse Practitioner allows me to continue to work closely with families, guiding them through the uncertain world of the NICU and supporting them to achieve a greater understanding of their baby's achievements. William and his family showed me the importance of celebrating each moment.

I strongly believe NIDCAP certification and training is essential for all health care workers, as the benefits it provides to families support these newborns long after their NICU journey ends. NIDCAP training has become more accessible to the southern hemisphere with the establishment of the Australasian NIDCAP training centre, opening these benefits to many more vulnerable newborns and their families. An additional benefit is having an on-site NIDCAP Trainer to closely supervise and support trainees throughout their NIDCAP journey.

\section{References}

1. Cundy TP, Gardener GJ, Andersen CC, Kirby CP, McBride CA, Teague WJ. Fetscopic endaluminal tracheal occlusion (FETO) for congenital diaphragmatic hernia in Australia and New Zealand:

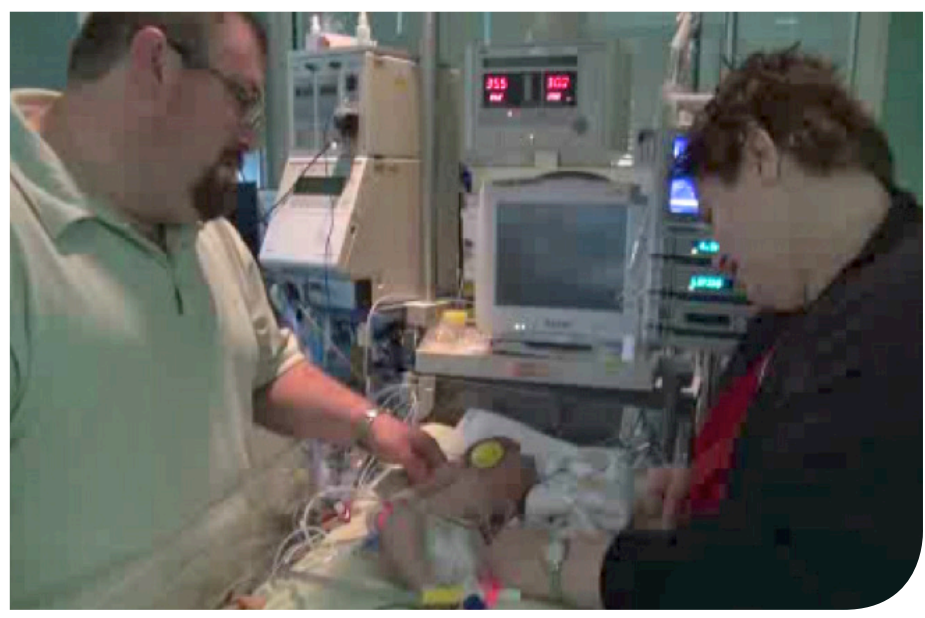

William with his parents Grant and Olivia

Are we willing, able, both or neither? Journal of Paediatrics and Child Health. 2014; 50: 226-233.

2. Als H. Guidelines for advanced NIDCAP practicum: Following an infant and family from admission to discharge and transition to the home. NIDCAP Federation International. 2015. Retrieved from http://Nidcap.org.

\section{Disclosure}

The images and identities used in this presentation have been included with the consent of Olivia and Grant Schrader.

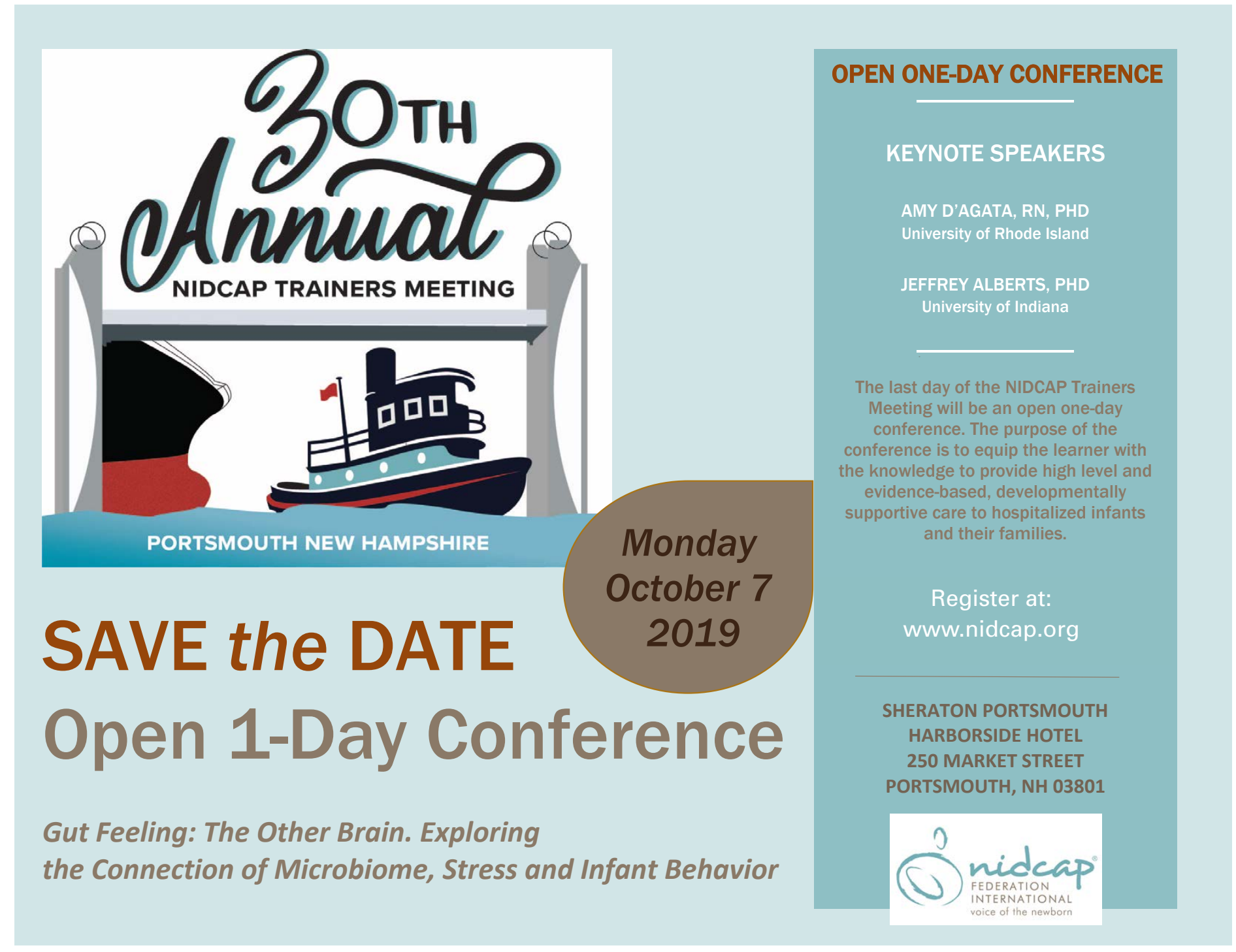

